\title{
Escenarios de inclusión y exclusión urbana. El caso de la migración venezolana en Cali, Colombia
}

Ana Melisa Pardo Montaño

Instituto de Geografía, Universidad Nacional Autónoma de México, México. http://orcid.org/oooo-0001-5959-530X

Recibido: 22 de marzo de 2019. Aceptado: 24 de octubre de 2019.

\begin{abstract}
Resumen
El objetivo de este estudio es analizar las prácticas de inclusión y exclusión urbana hacia la población venezolana residente en Cali - Colombia. Se considera la inclusión/ exclusión como un fenómeno multidimensional que puede ser entendido por aspectos económicos, sociales, políticos y territoriales. Se trabaja con entrevistas semiestructuradas a población venezolana realizadas en 2018, además de información hemerográfica relativa a la presencia e impacto de esta migración. En la primera parte se define que será entendido por inclusión/exclusión. Luego se caracteriza la migración venezolana hacia Colombia y por último se hace referencia a las prácticas de inclusión/exclusión en los contextos de interés.
\end{abstract}

Palabras clave: Migración. Inclusión. Exclusión. Colombia. Venezuela.

\section{Urban inclusion and exclusion scenarios. The case of venezuelan migration in Cali-Colombia}

\begin{abstract}
The primary objective is to analyze the urban inclusion and exclusion practices to the Venezuelan population living in Cali-Colombia. I consider inclusion/exclusion as a multidimensional phenomenon that can be interpreted through economic, social, political and territorial aspects. I work with semi-structured interviews of the Venezuelan population from 2018, and news articles regarding the presence and impact of this migration. In the first part of the document, I define what will be understood as inclusion/exclusion. Then, I characterize Venezuelan migration towards Colombia and finally, I analyze the inclusion/exclusion practices in the contexts of interest.
\end{abstract}




\section{Introducción}

Al nivel general, el aumento de los flujos migratorios es generado por las desigualdades y los desequilibrios económicos, políticos, espaciales y sociales que vive la población en distintos contextos internacionales. Como lo menciona Granado (2012:490), "el dispar reparto de la población entre las distintas partes del mundo, el injusto reparto de la riqueza y la desigual atribución de derechos y, por lo tanto, la desigualdad entre los tipos de vidas posibles en este mundo global, actúan como factores de dinamización del desplazamiento y como factores de producción de paradojas en el mundo". Este desplazamiento y dinamismo en las fronteras, si bien en el pasado se dio de los llamados países en vías de desarrollo, hacia los países desarrollados, las crisis económicas y políticas vividas en años recientes en distintos lugares, han generado movilidad entre lugares que no eran muy comunes anteriormente, como es el caso del crecimiento de migración intrarregional en Latinoamérica y en particular los desplazamientos de venezolanos hacia distintos contextos.

Venezuela tradicionalmente era un país receptor de población migrante; sin embargo, en los últimos años, este patrón se ha revertido y en la actualidad los cambios en el modelo político implementado y la inestabilidad económica derivada de éste, han generado un importante crecimiento de la población venezolana que se ve obligada a desplazarse hacia otros lugares (Castillo y Reguant, 2017). De acuerdo con la Organización Internacional de las Migraciones (OIM, 2018), entre 2015 y 2017, el número de población venezolana en el exterior pasó de 700 mil personas a un millón 600 mil.

Sobre el número de venezolanos que se encuentran residiendo fuera de su país hay varias investigaciones. Por ejemplo, de acuerdo con De la Vega y Vargas (2014), las cifras extraoficiales señalaban que existían más de un millón quinientos mil venezolanos en el exterior, lo que representa el 5\% de la población nacional. Entre los países a los cuales han ingresado recientemente estos venezolanos sobresalen: Colombia, España, Panamá, Chile, Argentina, México, Estados Unidos y Canadá. En este sentido, un elemento importante a destacar es que en la región se han observado distintos cambios en las políticas migratorias que han dificultado el ingreso de migrantes a países que si bien no eran importantes receptores de población extranjera, no tenían mayores requisitos para su ingreso. Estas restricciones han sido más notorias para el caso de los venezolanos, quienes en muchos casos se ven obligados a migrar incluso sin su pasaporte.

Colombia figura en la actualidad, como ya se mencionó, entre los principales países receptores de población venezolana. En términos generales, ha sido históricamente un país expulsor de población y no receptor. Esto se hace evidente incluso en la falta de una política migratoria nacional, la cual ha estado en constante discusión por varios años. Dicha discusión se ha centrado principalmente en la población colombiana que se encuentra en distintos destinos y no en las estrategias y/o programas para la población extranjera que actualmente reside en el país. A pesar de esto, el número de venezolanos que han ingresado al país se ha incrementado de manera constante, en ocasiones como una estrategia para llegar hacia otros países y en otros casos, como lugar de destino.

Cali ${ }^{1}$ (ver Figura 1) en particular, figura como una de las ciudades colombianas en las cuales la población venezolana ingresaba de manera temporal, para posteriormente continuar su tránsito hacia otros destinos latinoamericanos como Perú, Ecuador o Chile. Sin embargo, las condiciones actuales de la población en dichos destinos y algunas facilidades de incorporación al mercado laboral en Cali (informal casi en su mayoría), han derivado en que esta población se establezca de manera más permanente en la ciudad, lo que hace necesario el estudio de las prácticas de inclusión y exclusión hacia esta población. 
Considerando los aspectos antes mencionados, el objetivo del presente artículo será analizar las prácticas de inclusión y exclusión urbana de la población venezolana residente en Cali Colombia, como un caso que permite tener la visión tanto de la migración de tránsito como la que se queda. Para cumplir con el objetivo propuesto, en la primera parte se define qué será entendido por inclusión/exclusión. En la segunda parte, se caracterizará, de manera general, la migración venezolana hacia Colombia, mientras que en un tercer momento, se hará referencia a las características de inclusión y exclusión de esta población en el destino de interés. Se trabaja con entrevistas semiestructuradas a población venezolana residente y de tránsito en Cali realizadas en 2018, además de información hemerográfica relativa a la presencia e impacto de esta migración. Se realizaron en total 21 entrevistas tanto a hombres como mujeres mayores de edad que llevaran más de 6 meses viviendo en la ciudad. Dichas entrevistas se enfocaron en algunas características demográficas generales (edad, nivel educativo, profesión, estado civil, etc.); particularidades del contexto de salida; el proceso del cruce para llegar a Colombia y específicamente a Cali y, las características generales del contexto de llegada (mercado laboral, acceso a derechos, salud, educación, etc.).

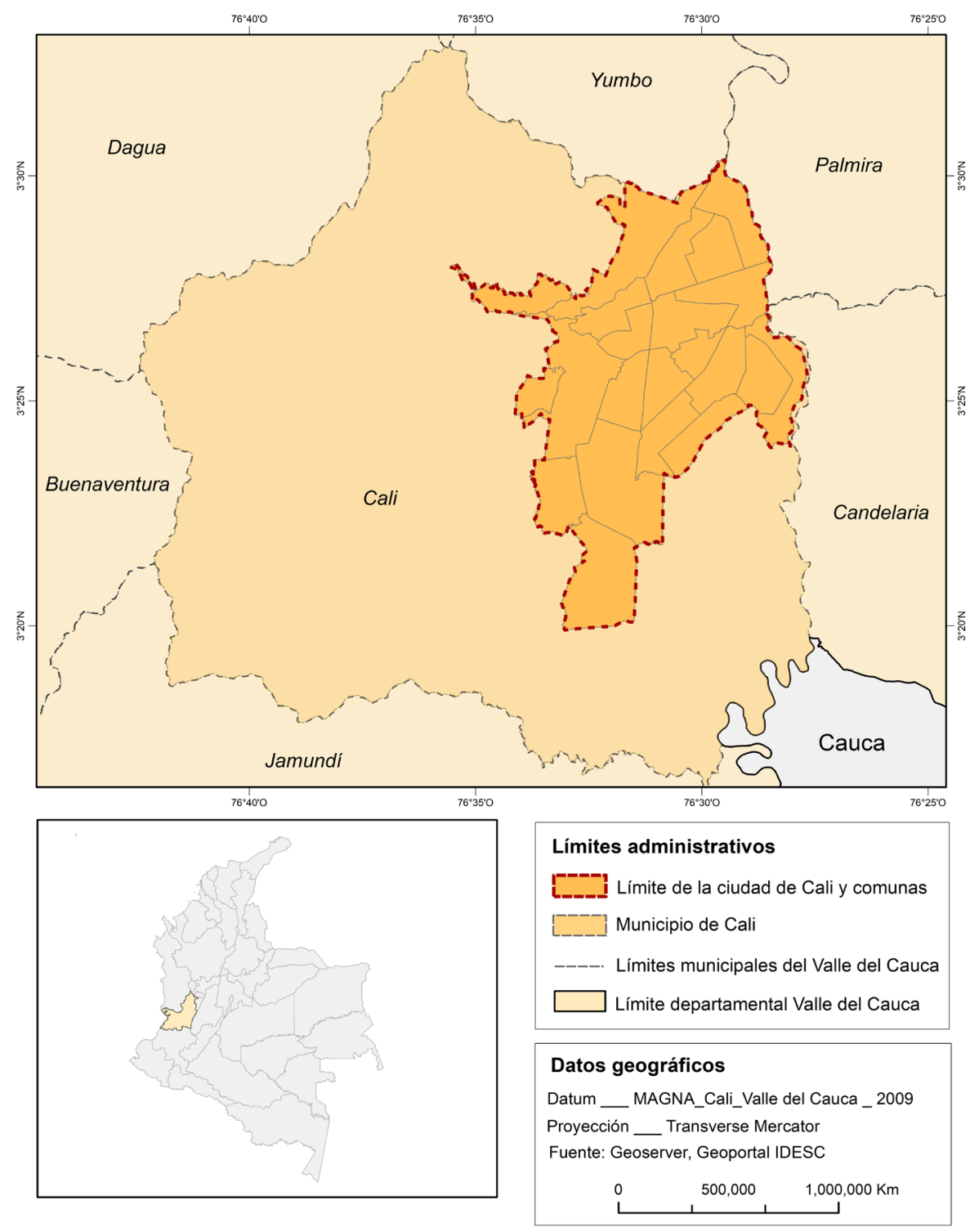

Figura 1. Mapa de ubicación de la ciudad de Cali - Colombia. Nota: La ciudad de Cali está conformada por área urbana que cuenta con 22 comunas, mientras que la zona rural está conformada por 15 corregimientos. La mayor concentración de la población venezolana se encuentra precisamente en el área urbana. Fuente: Elaborado por Aranza Pérez Sarmiento con base en información de la Infraestructura de Datos Espaciales de Santiago de Cali - IDESC. 


\section{Inclusión y exclusión en espacios urbanos}

Las ciudades son espacios complejos que presentan múltiples desafíos para su gestión. En términos generales, dicha gestión está inmersa en distintas problemáticas locales, regionales y nacionales que la dificultan, incluso si estamos refiriendo solo al caso de la población nacional. Para Baumann (2010), son precisamente las ciudades los espacios en los que se encierran los problemas globales, por lo que directamente las soluciones a problemas estructurales deben partir de estos espacios. Como se verá más adelante, cuando se hace referencia a la migración en espacios urbanos en América Latina, dada la novedad del fenómeno, son precisamente las acciones que se originan en estos espacios, las que han ocasionado tanto la inclusión como la exclusión de dicha población.

Para analizar los procesos de inclusión y exclusión de población migrante, se pueden considerar por un lado las posturas de la población receptora, mientras que por otro lado, se podría partir de las características y percepciones de la población inmigrante, las cuales podrían facilitar su incorporación al nuevo lugar de residencia. En el caso de esta investigación, el foco está puesto en las particularidades de la población migrante y la percepción que dicha población tiene ante algunas formas de inclusión o exclusión que les han manifestado en el destino. Es importante señalar que en el caso de la población venezolana, en la mayoría de los casos se incorpora de manera temporal o permanente en zonas urbanas, generalmente por la facilidad de obtener empleos (aunque sea en el mercado informal), por lo que las prácticas de inclusión y exclusión a las que se hará referencia, para este caso, refieren a aquellas que se dan en estos espacios urbanos.

El concepto de inclusión social se ha considerado como multidimensional y que afecta diferentes aspectos del desarrollo de la población. Se reconoce como un concepto ambiguo que se yuxtapone al de exclusión (Ratcliffe, 2000; Sandoval, 2016). En el caso de la población migrante, si se piensa en la inclusión como una característica que viene desde la sociedad receptora, entonces se podría entender como "el proceso mediante el cual las sociedades, principalmente encarnadas en el Estado social, incorporan de forma efectiva y sustantiva a diversas personas y grupos en los mecanismos articulados o interdependientes de redistribución y reconocimiento, para protegerlos de las desventajas que producen los ámbitos económico, político y social a ciertos grupos, con la finalidad última de que estas personas puedan lograr y llevar la vida que consideran vale la pena vivir" (Sandoval, 2016:86-87). Sin embargo, como ya se mencionó, el proceso de inclusión va de la mano con el de exclusión, por lo que es necesario enfocar el análisis no sólo en las características de la población de interés, sino que se hace necesario resaltar las percepciones y los discursos manifiestos por la población nacional, que en muchos casos discriminan y excluyen a las poblaciones "no privilegiadas", además de las percepciones de la población extranjera.

Sobre la inserción de población migrante, Nicolao (2011) refiere a distintos tipos de dificultades. El aumento de migración en condición de irregularidad, puede llegar a obstaculizar la inserción laboral, además de que puede ocasionar violaciones a los derechos humanos, distintas formas de discriminación y xenofobia, así como la aparición de políticas migratorias más restrictivas para mermar la llegada de extranjeros.

En esta investigación se trabaja con los postulados planteados por Haan y Maxwell (1998) y retomados por Azuero (2009), pero enfocándolos específicamente al tema de la inclusión. En este sentido, para dicho análisis, se tendrán en cuenta cuatro dimensiones del fenómeno: la inclusión/exclusión económica, que refiere a las facilidades o dificultades para incorporarse al mercado laboral y/o tener ingresos suficientes, lo que Haan y Maxwell (1998) denominan la privación económica; la inclusión/exclusión social y comunitaria, denominada por los autores privación social, y que en este 
caso referirá a los lazos sociales con la comunidad de destino y con otros migrantes, o la falta de estos; la inclusión/exclusión política, (privación política para los autores) y que referirá al nivel de conocimiento (o desconocimiento) y participación en temas políticos por parte de esta población; y por último, aunque no mencionado por estos autores, la inclusión/exclusión territorial, que hace mención a cuando algunos grupos más vulnerables no cuentan con las mismas posibilidades de acceso a los beneficios de la ciudad, como servicios, infraestructura y espacios de calidad que ofrece la ciudad al resto de grupos sociales (Mansilla y Fuenzalida, 2010), debido en este caso particular, a las restricciones impuestas por su condición de extranjeros.

\section{La migración venezolana reciente en Colombia}

El objetivo de este apartado es resaltar algunos elementos fundamentales de la presencia de población venezolana en Colombia y caracterizar los acontecimientos más relevantes que han sucedido en los últimos años, más que un ejercicio histórico exhaustivo de los movimientos migratorios derivados de las relaciones entre ambos países. Esto porque metodológicamente el trabajo se enfoca en la migración venezolana reciente.

Aunque tradicionalmente Venezuela había sido considerado un país de recepción de población extranjera, recientemente se ha observado una oleada emigratoria producto de la crisis económica, política y social que ha atravesado los últimos años. Sobre este tema, Muñoz (2016), resalta los movimientos fronterizos diarios y el incremento de la población venezolana hacia distintos países, entre ellos Colombia. Este último aspecto, se ha dado bajo la crisis nacional en un contexto de deterioro institucional, recesión económica y descomposición social, que de acuerdo con Castillo y Reguant (2017), ha empeorado a partir de 2010.

Sobre la emigración reciente en Venezuela, se ha hecho referencia a cuatro momentos importantes. El primero de ellos es el resultado de las devaluaciones y restricciones de transferencia y cambios de divisa durante el gobierno del presidente Luis Herrera Carpis (1979-1984). Un segundo momento se produjo después del llamado Caracazo en 1989 durante el gobierno de Carlos Andrés Pérez (1989-1993). La tercera corriente de emigración se dio durante el segundo gobierno de Rafael Caldera (1994-1999), periodo donde se intervinieron y cerraron los bancos en Venezuela, y en el que miles de venezolanos descendientes de inmigrantes europeos aprovecharon una serie de leyes y programas expedidos por países como España e Italia para obtener la doble ciudadanía. Finalmente, la última oleada inició con la llegada al poder de Hugo Chávez Frías y su proyecto bolivariano (Osorio, 2011).

De acuerdo con Migración Colombia (2017), a pesar de que existen muchos registros oficiales y no oficiales de la migración de venezolanos hacia Colombia, se calculaban para 2017 aproximadamente 550.000 personas, destacando entre las principales ciudades de llegada Bogotá, Barranquilla, Cúcuta, Medellín, Pasto, Cartagena, Cali, entre otras. En el caso particular de la ciudad de Cali, de acuerdo con información de la Secretaría de Seguridad y Justicia de la ciudad, aproximadamente se encuentran 37.000 venezolanos residiendo en dicha ciudad, muchos de ellos sin documentos.

Migración Colombia (2017) refiere a algunos aspectos fundamentales que se deben considerar para entender las dinámicas espaciales de los movimientos migratorios entre estos dos países. El primero de estos aspectos tiene que ver con la historia migratoria, ya que el movimiento entre ambos países no es reciente, incluso se caracterizaba por la migración de colombianos hacia Venezuela, quienes buscaban mejores oportunidades económicas, derivadas del auge petrolero del vecino país. Otro aspecto relevante es la 
presencia de diversos tipos de movimientos que dadas las dificultades metodológicas para poder registrarlos son más complicados de identificar: la migración pendular característica de las zonas fronterizas; la migración regular que refiere a aquellos que cuentan con su documentación para atravesar la frontera y que buscan establecer su residencia en Colombia; la migración de tránsito, que ha sido característica de los últimos años y que refiere a la búsqueda de nuevos destinos por parte de los venezolanos (Migración Colombia, 2017).

Uno de los aspectos a tener en cuenta de la migración entre Venezuela y Colombia es la frontera compartida antes mencionada, la cual ha facilitado, en ocasiones, los movimientos migratorios entre ambos países. Sin embargo, es importante mencionar la decisión del presidente venezolano Nicolás Maduro de cerrar la frontera en agosto de $2015^{2}$ (Louidor, 2018), lo que ha generado distintas consecuencias para la población venezolana que encontraba en la cercanía (territorial y cultural) con Colombia, una solución inmediata a las problemáticas acontecidas en su país. Sin embargo, de acuerdo a los testimonios recolectados durante el trabajo de campo en 2018, como se verá más adelante, las medidas tomadas no impidieron del todo los movimientos migratorios entre ambos países, aunque si han despuntado distintas problemáticas de seguridad y cambios en la política fronteriza entre ambos países (Linares, 2019).

En relación a Colombia como lugar de destino, si bien la población venezolana ha llegado a distintos departamentos en el país, particularmente donde se ha presentado mayor llegada de esta población, ha sido en los departamentos fronterizos (Arauca, Norte de Santander, La Guajira, principalmente). No obstante, poco a poco dicha población se ha ido desplazando a otros departamentos al interior del país, principalmente aquellos grupos que tenía como destino otros países: Ecuador, Chile, Panamá, Argentina, Brasil, entre otros (Plan de Respuesta Humanitaria, 2018). Entre estos lugares sobresalen: Bogotá, Medellín, Barranquilla y Cali, lugar de interés para esta investigación ${ }^{3}$.

Cali (ver mapa en anexo), la capital del departamento de Valle del Cauca, es la tercera ciudad con mayor población del país. De acuerdo con datos del Departamento Administrativo Nacional de Estadística DANE, los principales sectores económicos en los que se desenvuelve la población son el comercio, los servicios y la industria manufacturera. Sin embargo, es importante mencionar que la tasa de desempleo en la ciudad es más alta que la tasa a nivel nacional (12,3\% en Cali, 10,7\% en Colombia en 2016). Estas altas tasas de desempleo han derivado en que una importante porción de la población se dedique el empleo informal. En relación al tema migratorio, si bien tradicionalmente esta ciudad no ha sido receptora de migración internacional, si ha recibido población inmigrante proveniente principalmente del pacífico colombiano (Castañeda, 1993).

El empleo informal ha sido la principal fuente de ingresos de la población migrante tanto interna como la proveniente de Venezuela, siendo el transporte público y los semáforos, los espacios donde la población venezolana se ha insertado principalmente, no solo en Cali, sino en las distintas ciudades del país.

Las profundas desigualdades sociales, económicas y espaciales que actualmente viven los venezolanos tanto en Colombia en general como en Cali en particular, requieren una visión multidimensional, que entre otros factores se han visto afectadas por las pocas o nulas políticas que tiene Colombia referentes al tema migratorio, además de la

2 El cierre fronterizo se prolongó durante un año. A pesar de esto, en 2015 Migración Colombia registró la entrada de 329.478 ciudadanos venezolanos y la salida de 314.666 nacionales de este país (Migración Colombia, 2017). 
falta de acceso a servicios y un mercado laboral formal, como se verá en los apartados siguientes.

\section{Inclusión/exclusión económica}

La inclusión/excusión económica refiere a las facilidades o dificultades que tuvieron los migrantes para incorporarse al mercado laboral. Como ya se mencionó, la tasa de desempleo en Cali, es alta; sin embargo, dicha tasa aumenta en el caso de los venezolanos hasta $34,2 \%{ }^{4}$. De acuerdo con el Observatorio del Proyecto Migración Venezuela, en el caso de los venezolanos en Cali, predomina el trabajo temporal e independiente y en su mayoría se dedican particularmente al comercio informal (Acosta, 2019). De acuerdo con las entrevistas realizadas, un primer aspecto a resaltar es que la falta de trabajo, y de recursos para satisfacer sus necesidades básicas, son algunas de las principales causas para que dicha población decida migrar hacia otros lugares. Por otra parte, si bien muchos logran insertarse al mercado laboral (formal o informal), la mayoría lo hacen en actividades que no corresponden con las actividades o trabajos que desempeñaban en sus lugares de origen,

"y yo vendría siendo como (clase socio-económica) media-alta, yo tenía carro, teníamos una posición familiar... distribuidoras de productos lácteos, entonces éramos como quien dice muy conocidos en la ciudad que estábamos. Trabajaba primero familiarmente, a medida que se fue poniendo la situación más difícil se tuvo que quedar uno sin trabajo, y después me puse a trabajar en cuestiones de comida y eso, como yo soy chef, pero no... nada, cada día era más imposible, imposible... fui emplea, pasé por ser empleada también, pero gastaba más en el pasaje que lo que me ganaba en la semana, entonces recibimos maltrato, porque allá no le dan comida a los empleados empezando por ahí, entonces dije no, no vale la pena ni que salga a trabajar, llegó un momento en el que no hacía nada en la casa, porque salía más económico que ni saliera, vendí el carro y ahí fue que decidí ya familiarmente. Les dije que me tenía que venir pues, no había otra cosa, yo tengo 3 hijos: tengo uno de 20 años, un niño de 17 años y una niña de 3 , y decidí primero sacar al mayor al de 20 años, a él fue al primero que dije "bueno sal tu primero" y como quien dice lo saque, como si lo echaras así al mundo". (Mujer, 45 años).

“En Venezuela, estudiaba ingeniería mecánica, pero lo tuve que dejar por la misma situación del país, que, si estudiaba, no trabajaba, y si trabajaba, no podía estudiar, porque me afectaba mucho; $y$ desde que la cosa se empezó a poner un poquito más apretada acá, cada día más apretada, tuve que abandonar los estudios para poder trabajar y para poder sostener a la familia porque... no nos alcanzaba... aquí como ve, trabajo en el semáforo, vendiendo lo que puedo..." (Hombre, 26 años).

Si bien en otros contextos receptores de población extranjera se ha hecho referencia a cómo los migrantes han sido víctimas de racismo y xenofobia a la hora de intentar ingresar al mercado laboral (Rojas et al., 2015; Pardo, 2018), en el caso de los venezolanos entrevistados se pudo observar algunas muestras de inclusión y otras de exclusión por parte de los empleadores o compañeros de trabajo. Sobre facilidades para incorporarse al mercado laboral, una de las entrevistadas mencionó que:

"pues lo difícil es encontrar un espacio para trabajar, yo intenté vender dulces en 
el MIO, pero los mismos vendedores colombianos me bajaban, que porque no era de acá, que me fuera para otro lado", por eso ahora me pongo en este semáforo, aquí somos varios venezolanos" (Hombre, 23 años).

"veía que muchos venezolanos estaban en Bucaramanga y les estaba yendo bien, entonces yo por internet me metía y vi planes de trabajo aquí en Cali, en páginas de chef, entonces yo no sé si cosas de Dios, yo llene la planilla que estaban pidiendo y me llamaron de una vez inmediatamente por internet me escribieron, estaban pidiendo una empleada acá para Cali, para Holguines, entonces yo le dije al chef que yo no era de aquí pues, que yo era venezolana, y que en sí yo no venía todavía pues... que estaba planificando el viaje, ¿pero cuánto te tardas? Empezamos a hablar y entonces el chef me dijo: "bueno para este negocio no vas a quedar, pero tienes como 21 días en poder tener chance, porque se va abrir otro restaurante, entonces si en 21 días todavía estas, pues ahí tienes el trabajo" así duramos con comunicación, hable con la otra jefa, después nos hicimos video llamadas y me contrataron así, entonces ya yo le dije que cuánto necesitaba en dinero para yo poder llegar y alquilar, porque yo no conocía aquí a nadie, yél me dijo que no, que él me recibía en su casa, y así fue sin conocer porque yo decía uno nunca sabe, yo me vine muy arriesgada, yo lo ponía en oración "bueno diosito si tú piensas que algo malo me va a pasar allá, pues que me pierda en el autobús, que ese señor nunca llegue a buscarme"... (Mujer, 45 años).

Sin embargo, esta misma entrevistada sufrió algunas formas de discriminación por parte de sus compañeros de trabajo, que de acuerdo a su percepción tuvieron relación con su nacionalidad:

"ella (compañera de trabajo) me ha tratado muy mal, de hecho el primer mes de trabajo delante de todo el mundo me dijo que yo no servía y me tiró un trapo en la cara, y yo me acuerdo que yo agarre el pañuelo y le dije "eres una grosera de verdad te falta educación y yo podría ser tu mamá" ella tiene son 19 años y yo me quite la filipina que es mi chaqueta de trabajo, y dije "renuncio", yo renuncie ese día, y me acuerdo que llamaron a mi jefa, yo me puse a llorar porque no podía controlar de la rabia, del dolor, de ver que ella me odiaba, yo les decía ellos es que ella me odia porque soy venezolana, o sea a ella se le ve el rechazo y entonces ese día mi jefa me calmo todavía me dijo que no que ella sabía que yo estaba aprendiendo, y hablaron con ella pero a medida que van pasando los meses ella se calma como por días, y a los días ella vuelve a intentar ofenderme de cualquier manera y me lastima" (Mujer, 45 años).

Otro fenómeno que tiene relación con la exclusión económica, es la precariedad laboral que afecta a muchos de los venezolanos que residen tanto en Cali como en otras ciudades de Colombia y en otros contextos de la región, donde recientemente se ha visto un aumento del fenómeno migratorio. Tal es el caso por ejemplo de los inmigrantes en Chile que de acuerdo con el estudio realizado por Valenzuela y otros colegas en 2014, son los migrantes los que se ven obligados a trabajar en jornadas laborales más extensas o en trabajos no calificados, a pesar de sus altos niveles de escolaridad, pero que dadas las condiciones migratorias en las que se encuentran en los lugares de destino (en su mayoría en condiciones irregulares), si bien en ocasiones encuentran empleos con facilidad, esto es porque para los empleadores, resulta mucho más económico contratarlos, pues no les pagan las prestaciones a las que tendrían derecho. En el caso de los venezolanos en Cali, se pudo observar que si bien hay dificultades para ingresar al mercado de laboral formal, principalmente por la carencia de documentos, y en algunas ocasiones han logrado encontrar trabajos formales, para muchos, la opción ha sido el mercado informal, principalmente la venta de productos en los autobuses y los semáforos. 


\begin{abstract}
"Tengo cinco meses viviendo aquí en Cali, he sobrevivido trabajando en la calle, vendo bolsas para la basura, masmelos, caramelos o galletas, diferentes cosas que he tenido que vender porque tengo a mi esposa y a mi hijo aquí, entonces para poder sobrevivir, como no tengo el permiso permanente y lo estoy esperando en estos momentos, he tenido que trabajar de esa manera para poder sustentarme" (Entrevista a Grehemi Mijael Rojas, de 26 años, residente en Cali, disponible en https://www.elpais.com.co/cali/sigue-la-ola-de-venezolanos-en-cuatro-historiasde-supervivencia-en-las-calles.html).
\end{abstract}

Tanto las dificultades para encontrar un trabajo estable en el que cuenten con todas las prestaciones sociales que por ley tienen derecho, o el hecho de que la mayor fuente de empleos sea el mercado informal, son las principales prácticas de exclusión económica de la que es víctima esta población. Por otra parte, algunos de los entrevistados señalaron como una práctica inclusiva el que, en ocasiones, pudiera conseguir empleos, a pesar de su carencia de documentos.

\title{
Inclusión/exclusión social y comunitaria
}

De acuerdo con Haan y Maxwell (1998), este tipo de inclusión refiere a los lazos sociales con la comunidad de destino y otros migrantes. En este sentido, es importante mencionar que dado que Colombia en general y Cali en particular, no han sido espacios tradicionalmente receptores de migración internacional, las muestras de aceptación y rechazo por parte de la comunidad originaria han sido diversas.

Uno de los principales problemas en este sentido también tiene que ver con el ámbito laboral, pues en ocasiones se acusa a las personas de origen venezolano, de abaratar los salarios, pues como ya se mencionó, muchas veces los empleadores prefieren contratar a personal sin documentos a los que les pueden pagar menos. De acuerdo con una entrevista realizada a la presidenta de la Unión de Trabajadoras Afrocolombianas del Servicio Doméstico (Utrasd) en febrero del presente año, por el diario El Colombiano:

\begin{abstract}
"con la llegada de mujeres de Venezuela se ha acentuado la precariedad de las condiciones para las empleadas del servicio doméstico y muchas de ellas cambian una remuneración mínima por una comida u hospedaje, lo que impacta también a las trabajadoras locales. Se debe exigir tanto el salario mínimo como las prestaciones sociales y horas extra, pero muchos empleadores se aprovechan de su situación, perjudicándolas a ellas y a muchas trabajadoras nacionales”. (Entrevista a María Roa, presidenta de la Unión de Trabajadoras Afrocolombianas del Servicio Doméstico, disponible en: https://www.elcolombiano.com/negocios/economia/en-que-trabajanlos-venezolanos-que-llegan-a-colombia-KJ10199333).
\end{abstract}

Este discurso se replica no solo entre quienes pertenecen a organizaciones de apoyo a algunos grupos vulnerables del país, como el caso de las mujeres afrocolombianas trabajadoras domésticas antes mencionado, sino que es una realidad que viven los migrantes venezolanos tanto en Cali como en otros contextos urbanos del país y que se mantiene, entre otras causas por las dificultades para que incluso las personas locales puedan acceder a un mercado laboral (tanto formal como informal):

“...los 3 meses que estuve allá (Bogotá), trabajé en el Transmilenio (tipo de transporte público en Bogotá) vendiendo galletas, mentas, todo eso; pero como le digo, la gente allá ya estaba hostigada de los venezolanos, cansada... a cada ratico uno... igual que aquí. Usted se monta en el MIO (tipo de transporte público en Cali), señora, cada ratico hay venezolanos... y yo sé que eso los aturde, ¿me entiendes?, la molestia, 
pero no lo haces con la intención de molestarlos, simplemente lo hacemos con la intención de trabajar. Por eso es que no... no me trepaba en el MIO, porque también me daba, pena, miedo, y los problemas con los colombianos, con los vendedores de que "No queremos venezolanos"... (Hombre, 22 años).

Las relaciones entre los venezolanos también son diversas. Como mencionaron algunos entrevistados, en ocasiones muchos que se han conocido en el tránsito por el país se apoyan mutuamente, por ejemplo para rentar viviendas, con la intención de disminuir los gastos que tienen que pagar. En otros casos, también se apoyan en la alimentación, cocinando en conjunto también para lograr ahorrar dinero.

Otras formas de colaboración entre compatriotas se dan a través de las redes sociales, en donde se publica información de trabajos disponibles, espacios para rentar, formas de enviar dinero o mercancías a Venezuela. Aunque también se pueden convertir en espacios de exclusión en la medida en que en ocasiones las personas afines al gobierno actual publican información que no va a acorde con los intereses de la mayoría de los integrantes de los grupos, lo que genera enfrentamientos virtuales entre los opositores.

\section{Inclusión/exclusión política}

Si bien dentro de la inclusión política se pueden consideran aspectos importantes como las asociaciones de migrantes, liderazgos y redes transnacionales ${ }^{5}$, en este caso, se hace énfasis en la falta de políticas de atención a dicha población en el destino, lo que en el caso de los venezolanos en Colombia ha generado distintas prácticas de inclusión y exclusión. El análisis se centra en este aspecto particularmente porque se considera que si bien las asociaciones de migrantes y otro tipo de manifestaciones de la esfera política en el tema migratorio, son principalmente iniciativas que vienen desde abajo, desde la misma comunidad en el destino, siendo la inclusión/exclusión política una manifestación principalmente desde arriba (desde las instituciones que deberían atender el tema migratorio).

Colombia se encuentra entre los países de la región que a pesar de los cambios en los flujos migratorios que ha vivido recientemente, no ha generado una reforma legislativa relevante en el tema y la aparición de algunas políticas o programas se han implementado derivadas de la emergencia y la improvisación ante la llegada masiva de población. El tema migratorio ha estado a cargo del Ministerio de Relaciones Exteriores que a través de la Unidad Administrativa Especial de Migración se ha encargado de la formulación de la política migratoria. Sin embargo y como se constató en el trabajo de campo realizado en la ciudad de Cali, en la oficina que pertenece a dicho Ministerio, las actividades que lleva a cabo han estado enfocadas en los trámites que deben llevar a cabo los colombianos que se encuentran en el extranjero y se ha dado una menor atención a aquellas que tienen que ver con la población extranjera que ingresa al país, aunque en los últimos años se ha dado un incremento de población especialmente venezolana que busca información general. Incluso las percepciones individuales de quienes trabajan en dicha oficina, pueden llegar a afectar la forma como se atiende a las necesidades de esta población. Esto se pudo constatar en la visita realizada al Centro Facilitador de Servicios Migratorios, que hace parte del Ministerio de Relaciones

5 Existen distintos grupos que apoyan a la población venezolana en Cali tales como Migrantes Triculor, Colvenz Valle del Cauca, además de distintos grupos en redes sociales como Facebook que buscan ofrecer información a sus connacionales sobre empleos, renta de departamentos o cuartos, reuniones de venezolanos en la ciudad, entre otras actividades. 
Exteriores y que se encuentra ubicado en la ciudad, donde un funcionario refirió a las distintas problemáticas que ha generado la llegada de venezolanos a la ciudad con afirmaciones como "Cali está afectada por la llegada de venezolanos" o "Colombia no tiene la culpa de que Venezuela esté como estä".

De acuerdo con una entrevista realizada al director de Migración Colombia por el diario el tiempo, "no hay nada más peligroso para un país que no saber qué extranjeros se encuentran dentro de su territorio". Este tipo de afirmaciones han servido como justificación para la realización de un censo de venezolanos en Colombia a través del Registro Administrativo de Migrantes Venezolanos - RAMV, el cual tenía como objetivo principal, ampliar la información disponible a cerca la población procedente del vecino país, que como se señala en el portal de Migración Colombia "no genera derechos de orden civil o político, ni el acceso a planes o programas sociales u otras garantías diferentes a las dispuestas en la oferta institucional de las entidades del Estado, de conformidad con las normas legales vigentes". Si bien la participación en este registro no es obligatoria, para que los venezolanos que no contaban con ningún permiso para residir en Colombia, resultaba indispensable realizarlo, ya que serían aquellos que hicieron dicho registro, los que podrían solicitar en un futuro nuevamente el Permiso Especial de Permanencia (PEP).

De acuerdo con el portal de Migración Colombia, este permiso especial, es el documento de identificación válido para personas de origen venezolano residentes en Colombia, el cual en teoría, les permite permanecer temporalmente en el país y acceder a servicios como salud, educación y principalmente trabajo. Para acceder a dicho permiso, los venezolanos deben haber ingresado al territorio nacional de manera regular por un puesto de control migratorio, lo que, de acuerdo con algunos de los entrevistados, no es muy común en muchos de los que actualmente se encuentran en el país. Adicionalmente no deben contar con antecedentes judiciales a nivel nacional e internacional, ni tener medidas de expulsión o deportación vigentes a la hora de solicitar el permiso. La vigencia de dicho permiso es de 90 días, prorrogables hasta por dos años, al cabo de los cuales se debe solicitar visa o abandonar el país.

Dicha medida, que si bien pretendía tener conocimiento de la población venezolana residente en el país y que los portadores pudieran acceder al mercado laboral y otros servicios, se ha convertido en el principal factor de exclusión, pues quien no cuenta con dicho documento, tiene restringidos sus derechos y como bien se observó durante el trabajo de campo en Cali, muchos de los venezolanos se ven obligados a dedicarse al trabajo informal, precisamente por la falta de este documento y cuando encuentran trabajos "formales" reciben salarios más bajos o no cuentan con la seguridad social obligatoria. Lo mismo ocurre con el acceso a servicios de salud y vivienda, pues para rentar, además de otros requisitos, les piden este documento.

"Yo vivía con la mamá de mi hija, nos separamos y yo empecé a trabajar por mi cuenta, pero ya no me rendía porque ya no era yo solo, sino que tenía que mantener a una niña. Por eso decidí venirme para acá, porque ya no me alcanzaba para mantener a mi hija. El problema acá es que no tengo el PEP, entonces encontrar trabajo ha sido muy complicado. Por medio del internet, había conseguido trabajo en una peluquería en Bogotá, pero cuando llegué y no tenía el PEP, no se pudo. Ahora estoy aquí (peluquería en Cali), solo que me tocan turnos largos y a veces no descanso, pero bueno, puedo trabajar" (Hombre, 21 años).

Por otra parte, muchos migrantes venezolanos, dada la migración de colombianos hacia dicho país, cuentan con familiares nacidos en Colombia, por lo que antes de acceder al PEP, prefieren solicitar la nacionalidad colombiana la cual les permitiría tener acceso a todos los servicios que por su condición de extranjeros, les han sido negados. 


\section{Inclusión/exclusión territorial}

La definición de inclusión/exclusión territorial alude a la falta de acceso a los beneficios, es decir, servicios, infraestructura y espacios de calidad que ofrece la ciudad al resto de grupos sociales (Mansilla y Fuenzalida, 2010) y en particular para este caso, a las restricciones atribuidas a las condiciones migratorias.

Cuando referimos a la inclusión/exclusión territorial, podemos también apuntar a otros conceptos que están relacionados y que pueden ayudar a explicar algunas formas de resistencia por parte de los migrantes para moverse en espacios que no les son familiares y tener derechos en estos. Uno de estos conceptos es el derecho a la ciudad, desarrollado por Lefebvre (1978) y que ha sido retomado por muchos autores para visibilizar las luchas de algunos colectivos por apropiarse y producir la ciudad, como lo menciona Raquel Rolnik en entrevista realizada por Dammert y Delgadillo (2018: 238) "el derecho a la ciudad, en la actualidad, es una especie de plataforma flotante que tiene la capacidad de articular movimientos y colectivos que luchan para poder tener el derecho de apropiarse de la ciudad en el sentido físico y material, como su espacio de vida, de prosperidad, de oportunidades".

Sin embargo, estas luchas por el territorio suelen verse minimizadas cuando se alude a migrantes irregulares, pues para evitar el impacto de estos movimientos, el Estado, con un discurso de protección hacia su población nacional, criminaliza estos grupos, anotando las problemáticas que "podrían" generar para los nacionales. Cali no se escapa de estas temáticas, lugar en el cual, los discursos oficiales también criminalizan a la población venezolana. Un ejemplo de este tipo de discursos proviene precisamente del Subsecretario de Seguridad y Justicia de Cali, quien en una entrevista en medios de comunicación apuntó a la permanencia de los venezolanos en espacios públicos como una invasión: "lo que se va a realizar es la restitución de un espacio público que fue invadido". Sobre este tema afirma que:

"esta invasión indirectamente o directamente ha provocado una caída estrepitosa dentro de los precios del metro cuadrado de la gente que vive ahí y está a punto de quebrar la mayoría de los negocios de las personas que trabajan en los alrededores, o sea que aquí estamos hablando de una afectación seria" (Pablo Uribe, el Subsecretario de Seguridad y Justicia de Cali. Entrevista disponible en: https://www. youtube.com/watch?v=7ubiTAR8fCc).

En el caso de la población venezolana en Cali, la mayoría de estas luchas por la ciudad tienen que ver con el derecho a una vivienda digna y a servicios básicos, que dada la falta de acceso a un permiso migratorio para trabajar, para muchos de estos migrantes, especialmente aquellos que van de tránsito, esto no es posible. Por lo tanto se "apropian" de espacios públicos como parques y zonas verdes, principalmente en franjas cercanas a la terminal de autobuses, donde establecen campamentos informales, por ser el primer lugar de llegada, o después de haber sido desalojados de la terminal, en zonas cercanas al río Cali, los cuales convierten en sus espacios de vida, de sobrevivencia. Sin embargo, esto ha generado una disputa por el espacio público entre estos migrantes que luchan por encontrar un lugar donde permanecer y la población nacional que refiere a una "invasión por parte de los venezolanos". Además, el Estado a través de instancias como la Secretaría de Seguridad, ha referido a problemas de salubridad, a la pérdida de valor del suelo (como se mencionó anteriormente) o su intrusión en otros espacios como el transporte público o los semáforos, en los que los venezolanos se han establecido en el mercado laboral informal.

En el caso particular de la migración irregular más que una inclusión territorial, a lo que se hace alusión es a una exclusión, lo que no sucede por ejemplo cuando se trata 
de movimientos migratorios regularizados, con recursos económicos, donde la presencia de población venezolana que establece negocios como restaurantes o invierten en la economía del país receptor no resulta "molesta" ni para el Estado, ni para los nacionales, quienes ven con buenos ojos la entrada de inversión extranjera. Por lo tanto, las diferencias en las estructuras urbanas se concentran en manos de la población privilegiada (estratos socio-económicos más altos), incluso de manera aislada a la condición de extranjería.

\section{Consideraciones finales}

Las continuas crisis económicas y políticas que se han presentado a nivel mundial, han generado, entre otras cosas, que los movimientos interregionales, sean cada vez más comunes en América Latina y el Caribe. Incluso se han generado desplazamientos de población poco habituales como la llegada a distintos países de América del Sur y Centroamérica de personas procedentes de Senegal, Ghana, Costa de Marfil, entre otros países africanos.

Este es el caso de la población venezolana quienes debido a la crisis política que se vive en dicho país y a los desequilibrios económicos que ésta ha generado, se han visto obligados a desplazarse hacia distintos destinos, entre los que sobresale el caso de Colombia, por la cercanía territorial y cultural y porque muchos de estos venezolanos son descendientes de colombianos que por diferentes circunstancias habían migrado en otros momentos hacia Venezuela.

Esta llegada masiva hacia un lugar que más que receptor de población, la ha expulsado, ha generado distintas prácticas de inclusión y exclusión hacia esta población. Para iniciar, se buscó señalar que los procesos de inclusión y exclusión son multidimensionales y que una persona puede estar incluida en relación a algunas dimensiones, pero excluida de otras. En este sentido, la definición de inclusión/exclusión presentada por De Haan y Maxwell (1998) y retomada por Azuero (2009), resultó conveniente para esta investigación, pues permitió mostrar algunas prácticas en temas relacionados con lo económico, lo social y lo político. Sin embargo, otra dimensión no considerada por estos autores que se exploró para el caso de los venezolanos residentes en Cali fue la inclusión/exclusión territorial, entendida por Mansilla y Fuenzalida (2010), como las formas en las que la población vulnerable accede a los beneficios que ofrece la ciudad al resto de grupos sociales. En este caso en particular, se hizo referencia también al derecho a la ciudad, como un concepto que permite entender la inclusión/exclusión territorial. En este aspecto se considera relevante señalar la importancia de estudios que refieran a este concepto y su relación con la migración internacional y que aunque existen algunas investigaciones que han estudiado dicha relación (Matossian, 2015), poco se ha trabajado sobre la migración regional.

Si bien esta investigación no pretende ser un estudio exhaustivo de la presencia venezolana en Cali- Colombia, permitió tener un primer diagnóstico de la llegada de un grupo poblacional, que parte de sus lugares de origen en condiciones muy difíciles y que intenta ingresar al país con el objetivo de mejorar sus condiciones económicas y sociales y las de sus familiares en Venezuela a través del envío de remesas, pero que se enfrenta también con obstáculos a su llegada. Un ejemplo de esto tiene que ver con las características económicas y los niveles educativos de la población migrante en los lugares de origen, que no necesariamente se corresponden con la incorporación al mercado laboral en el destino, pues muchos deben dedicarse a actividades informales, mal remuneradas y sin acceso a seguridad social tanto por su condición de migrantes (y su nacionalidad de origen), como por la ausencia de documentos para permanecer 
y trabajar en el país, aspecto que no solo se ha dado en la ciudad de Cali, sino en otros lugares de llegada tanto en Colombia como en otros destinos. Estos aspectos muestran la necesidad de realizar más estudios que refieran tanto a llegada de este colectivo de migrantes, como a los rasgos de discriminación y xenofobia que han dificultado la inclusión de dicha población.

En el ámbito económico se resaltaron los obstáculos para ingresar al mercado laboral formal y/o la precariedad en la cual se insertan, aunque también, de acuerdo a la percepción de los entrevistados, las facilidades para incorporarse al mercado informal, aspecto que no sucede en otras ciudades del país. En el aspecto social sobresalieron las dificultades en las relaciones entre los nacionales y los venezolanos, que en ocasiones se exacerban debido a los discursos estatales que buscan criminalizar la presencia de venezolanos, aunque también resultaron importantes para los entrevistados, las muestras de apoyo y solidaridad por parte de algunas personas.

Dos de las dimensiones que resultaron más llamativas en este estudio fueron la política y la territorial. En el aspecto político destaca la intención de otorgar un documento de identidad y de conocer las principales características de los venezolanos en Colombia a partir del Permiso Especial de Permanencia, pero que termina convirtiéndose en un instrumento de exclusión, pues difícilmente los venezolanos que no cuentan con dicho permiso, logran acceder al mercado laboral formal o a servicios como la salud, la vivienda, la educación, etc. Por otro parte, en el aspecto territorial, la presencia de esta población ha derivado en disputas por el espacio público, que han originado desalojos, violaciones a los derechos humanos y discursos xenofóbicos por parte de las autoridades, para evitar la "invasión" de población que no cuenta con los recursos necesarios para establecerse en el país con la documentación necesaria.

La llegada de esta población a distintos contextos urbanos del país demanda una mirada más allá de la atención inmediata, se requiere del reconocimiento de esta población no solo a través de mecanismos oficiales como los permisos para residir, sino de la promulgación de leyes que defiendan sus derechos y de concientizarse de que en la actualidad, la migración intrarregional cada vez será un fenómeno más común.

Agradecimiento: Se agradece al proyecto "Crisis y migración de población venezolana... entre la desprotección y seguridad jurídica en ciudades latinoamericanas", el cual hace parte de la Red Temática Migräre Migraciones y Movilidades, por compartir su instrumento de recolección de información, el cual sirvió de base para diseñar las herramientas de recolección para la presente investigación. 


\section{Q Bibliografía}

"Alarcón, P. (2019). Proyecto migración Venezuela. Recuperado de https:// migravenezuela.com/ (Fecha de consulta octubre 20 de 2019).

» Azuero, A. (2009). Capital social e inclusión social: algunos elementos para la política social en Colombia. Cuadernos de Administración 41, 151-168.

»Bauman, Z. (2010). Vivir con extranjeros. Carajillo: café con picardía. Revista Digital del Programa en Gestión de la Ciudad, 2(6).

»Castañeda, W. (1993). Patrones de migración hacia Bogotá, Medellín, Cali y Barranquilla. Un estudio comparativo. Revista Coyuntura Social, Centro de Investigación Económica y Social, 121 - 135.

»Castillo, T., y Reguant, M. (2017). Percepciones sobre la migración venezolana: causas, España como destino, expectativas de retorno. Revista del Instituto Universitario de Estudios sobre Migraciones, 41, 133-163.

»Dammert, M., y Delgadillo, V. (2019). América Latina, nuevas y viejas desigualdades urbanas. Entrevista a Raquel Rolnik. Revista Andamios, 16(39), 237-251.

"De Haan, A., and Maxwell, S. (1998). Poverty and Social Exclusion in North and South. IDS Bulletin 29(1), 1-19.

»De la Vega, I., y Vargas, C. (2014). Emigración intelectual y general en Venezuela: Una mirada desde dos fuentes de información. Bitácora-e Revista Electrónica Latinoamericana de Estudios Sociales, Históricos y Culturales de la Ciencia y la Tecnología, 001, 66-92.

" García R., y Gainza, P. (2014). Economía, migración y política migratoria en Sudamérica: Avances y desafíos. Migración y desarrollo, 23, 69-97.

"Granado, V. (2012). ¿Derecho de fuga? Derecho de migración y nacionalidad cosmopolita. ARBOR Ciencia, Pensamiento y Cultura, 188(755), 489- 502.

»Lefebvre, H. (1974). La producción del espacio. España: Entre líneas, 2013.

"Linares, R. (2019). Seguridad y política fronteriza: una mirada a la situación de la frontera entre Venezuela y Colombia. OPERA, 24, 135-156.

»Louidor Wooldy, E. (2018). La migración forzada venezolana a Colombia (20152018): de una revisión documental a los esbozos de un análisis coyuntural y estructural. En: J. Koechlin y J. Eguren (Eds.), El éxodo venezolano: entre el exilio y la emigración (21-46). Perú: Colección OBIMID, volumen No. 4.

»Mansilla Q, P., y Fuenzalida D, M. (2010). Procesos de desarrollo urbanoregional y exclusión territorial: Nuevas formas de urbanización en el área metropolitana de Valparaíso. Estudio de caso ciudad de Curauma. Revista INVI, 25(69), 103-123.

" Matossian, B. (2015). Derecho a la ciudad en San Carlos de Bariloche: inserción residencial y política de migrantes. Revista Universitaria de Geografía, 24(1), 1139.

" Migración, Ministerio de Relaciones Exteriores. (2017). Radiografía de Venezolanos en Colombia. Recuperado de http://www.migracioncolombia.gov. co/venezuela/radiografia_web.pdf (Fecha de consulta marzo 17 de 2019). 
» Nicolao, J. (2011). Migraciones intrarregionales en Sudamérica. Boletín Real Instituto Elcano, 10(134), 1-10.

" Osorio, E. (2011). La emigración internacional venezolana a los Estados Unidos de América, durante el lapso 2003-2008. Ponencia presentada en el V Encuentro Nacional de Demógrafos y Estudiosos de la Población, Universidad Central de Venezuela, Caracas.

"Pardo, A. (2018). Del discurso a la acción en el derecho al libre tránsito para la población extranjera residente en México. En C. Bobes, (Coord.), Política migratoria y derechos de los migrantes en México. México: Editorial Facultad Latinoamericana de Ciencias Sociales.

" Ratcliffe, P. (2000). Is the assertion of minority identity compatible with the idea of a socially inclusive society? In A. Stewart y P. Askonas, (Eds.), Social inclusion: possibilities and tensions. (169-185). London: Palgrave MacMillan.

»Rojas Pedemonte N., Amode, N., y Vásquez Rencoret, J. (2015). Racismo y matrices de "inclusión" de la migración haitiana en Chile: elementos conceptuales y contextuales para la discusión, Polis 14(42), 217-245.

"Sandoval, B. (2016). ¿Inclusión en qué? Conceptualizando la inclusión social. EHQUIDAD, Revista Internacional de Políticas de Bienestar y Trabajo Social, 5, 71108.

»Valenzuela P., Riveros, K., Palomo, N., Araya, O., Campos, B. Salazar, C. y Tavie, C. (2014). Integración laboral de los inmigrantes haitianos, dominicanos y colombianos en Santiago de Chile. Antropologías del Sur, 1(2), 101-121.

\section{Ana Melisa Pardo Montaño / analissa18@gmail.com}

Académica en el Instituto de Geografía de la Universidad Nacional Autónoma de México (UNAM) y profesora del Posgrado de Urbanismo en la misma institución. Pertenece al Sistema Nacional de Investigadores del CONACyT. Sus trabajos de investigación se enfocan en temas relacionados con la migración internacional, las remesas, el impacto de la migración en las ciudades y la violencia y los homicidios en América Latina. 